\title{
BMJ Open Adverse birth outcomes in Guangdong province, China, 2014-2017: a spatiotemporal analysis of 2.9 million births
}

\author{
Huazhang Miao, ${ }^{1}$ Bing Li, ${ }^{1}$ Wu Li, ${ }^{1}$ Fei Yao, ${ }^{1}$ Yuliang Chen, ${ }^{2}$ Ruyin Chen, ${ }^{3}$ \\ Jiumin Lin, ${ }^{4}$ Yuntao Wu, ${ }^{1} \mathrm{Pi}$ Guo, ${ }^{2}$ Qingguo Zhao ${ }^{5}$
}

To cite: Miao H, Li B,

Li W, et al. Adverse birth outcomes in Guangdong province, China, 2014-2017: a spatiotemporal analysis of 2.9 million births. BMJ Open 2019;9:e030629. doi:10.1136/ bmjopen-2019-030629

- Prepublication history and additional material for this paper are available online. To view these files, please visit the journal online (http://dx.doi. org/10.1136/bmjopen-2019030629).

$\mathrm{HM}, \mathrm{BL}, \mathrm{WL}$ and FY contributed equally.

$P G$ and $Q Z$ contributed equally.

$\mathrm{HM}, \mathrm{BL}, \mathrm{WL}$ and $\mathrm{FY}$ are joint first authors.

$P G$ and $Q Z$ are joint senior authors.

Received 27 March 2019 Revised 08 0ctober 2019 Accepted 09 October 2019

Check for updates

(c) Author(s) (or their employer(s)) 2019. Re-use permitted under CC BY-NC. No commercial re-use. See rights and permissions. Published by BMJ.

For numbered affiliations see end of article.

Correspondence to

DrPi Guo; pguo@stu.edu.cn

Dr Qingguo Zhao; zqgfrost@126.com

\section{ABSTRACT}

Objectives Adverse birth outcomes pose a great threat to the public health and bring a heavy burden of disease in China. A comprehensive examination of the temporal and spatial trends of preterm birth (PTB), low birth weight (LBW) and small for gestational age (SGA) epidemics can provide some elementary information for subsequent aetiological and epidemiological studies. This study aimed to characterise the spatiotemporal features of PTB, LBW and SGA based on a large cohort of live births in China. Design Spatiotemporal descriptive analysis was performed in Guangdong province, China, from 2014 to 2017.

Setting Data involving 2917098 live births in Guangdong province, China from 2014 to 2017 was collected from Guangdong Birth Certificate System. Information was collected, including the date of birth, gestational age in week, birth weight, sex of the infant, age of the mother and registered residence of the mother.

Results The estimated rate of PTB, LBW and SGA was $4.16 \%, 4.14 \%$ and $12.86 \%$, respectively. For temporal trends, the rates of PTB, LBW and SGA showed seasonal fluctuations, especially for LBW and SGA. In addition, there were regional differences in the rates of PTB, LBW and SGA between the Pearl River Delta and Non-Pearl River Delta regions. From 2014 to 2017, the high rates of PTB and LBW expanded from the Pearl River Delta region to the Non-Pearl River Delta regions. However, compared with the Pearl River Delta region, the rate of SGA was higher in the Non-Pearl River Delta regions on the whole.

Conclusion The findings of this study contribute to the understanding of the aetiology and epidemiology of PTB, LBW and SGA in south China.

\section{INTRODUCTION}

Previous studies ${ }^{1} 2$ suggested that severe infant morbidity and mortality partly resulted from adverse birth outcomes including preterm birth (PTB), low birth weight (LBW) and small for gestational age (SGA). PTB is defined as a live-birth infant with less than 37 complete weeks of gestation. ${ }^{3} \mathrm{LBW}$ is defined as a live-birth infant weighing less than 2500 $\mathrm{g}$ at birth. ${ }^{4}$ SGA is defined as an infant whose

\section{Strengths and limitations of this study}

- This study is a spatiotemporal descriptive analysis to reveal the current situation of adverse birth outcomes in Guangdong, south China.

- The study involves a cohort of nearly 2.9 million live births and further enhances our understanding of the temporal trend and spatial distribution of adverse pregnancy outcomes in south China.

- Multiple adverse pregnancy outcomes including preterm birth, low birth weight and small for gestational age have been investigated and compared in terms of their temporal trend and spatial distribution.

- As a descriptive analysis, this study was unable to identify the causal relationship between spatiotemporal factors and adverse pregnancy outcomes.

- Delays in reporting birth certificate data at small hospitals in different cities may cause bias.

birth weight falls below the 10th percentile by sex and gestational week of all singleton live births in a region. ${ }^{5}$ With the development and progress of society and the continuous improvement of the level of medical care, the health condition of infants and young children has been significantly improved. However, adverse pregnancy outcomes such as PTB, LBW and SGA have not been effectively controlled, which has become an important risk factor for infant health. PTB rates were reported ranging from $6.2 \%$ to $11.9 \%$ of live births in some developed and developing countries. ${ }^{6}$ In fact, the incidence of LBW in developed countries is still high and even rising. ${ }^{7}$ Among 135 million infants born in low-income and middleincome countries in 2010, it is estimated that 29.7 million $(22 \%)$ were term births of SGA and 2.8 million $(2.1 \%)$ were PTBs of SGA. ${ }^{8}$ In Guangzhou city of south China, a PTB rate of $5.6 \%$ has been reported in a previous study. ${ }^{9}$ A retrospective study involving 39 hospitals of different levels from 14 provinces and 
autonomous regions in China throughout 2011 reported that a total of 7474 cases were diagnosed as LBW (incidence $=7.2 \%) .{ }^{10}$ Overall, these adverse birth outcomes pose a great threat to the health of infants.

Additionally, the adverse outcomes of PTB, LBW and SGA may also increase the risk of chronic diseases or developmental outcomes later in life. ${ }^{1112}$ These facts show that PTB, LBW and SGA are still challenging problems of public health in many countries. Thus, further research is needed to investigate the epidemiology of these problems more comprehensively. Many previous studies described significant seasonal variations of PTB, LBW or SGA with remarkable differences between regions. ${ }^{13} 14$ However, some research did not detect an association between temperature and adverse pregnancy outcome. ${ }^{15-17}$ In fact, the conditions of evidence differed among different regions and studies. The complexity of PTB, LBW, SGA and relevant risk factors in the individual, social and spatial levels often makes the causal relationship between identified risks and responses non-stationary in space and time. A comprehensive examination of the temporal and spatial trends of PTB, LBW and SGA can provide some basic elements for subsequent aetiological and epidemiological studies.

As the southern gate of China, Guangdong province has the most developed economic and social level in south China. ${ }^{18}$ However, there are still regional differences in the industrial development, the degree of medical care and the level of education of the local residents that cannot be ignored. These factors may have an impact on the fertility status of local residents in Guangdong province. In addition, more recent data about the fertility status of local residents have not been reported. There is an urgent need to provide an overall description of the fertility situation of the local population in order to carry out some other follow-up exploratory studies. Therefore, in order to fill in the gap, we performed a spatiotemporal analysis of PTB, LBW and SGA, based on a large cohort involving approximately 3 million newborns in Guangdong province, China from 2014 to 2017. This study is more convincing because of the relatively large investigated samples. Additionally, this study analysed regional differences of PTB, LBW and SGA between the Pearl River Delta and Non-Pearl River Delta regions. In general, the Pearl River Delta regions represent economically developed regions in Guangdong province, while Non-Pearl River Delta regions represent relatively underdeveloped regions. The findings of this study will contribute to the understanding of the aetiology and epidemiology of PTB, LBW and SGA and the design of prevention and intervention strategies for specific geographical areas and highrisk populations.

\section{MATERIALS AND METHODS}

\section{Patient and public involvement}

All birth data in this study were obtain from Guangdong Birth Certificate System and were only used for statistical analysis. Information of newborn and mothers across Guangdong province was collected in this study. No patients or public were involved in development of research question, study design, conduction of research and measurement of outcome. There are no plans of disseminating research results to participants.

\section{Data preparation}

All birth data was collected from the Guangdong Birth Certificate System, which collects information of infants and young children from medical institutions in Guangdong province. After childbirth, obstetric medical staff put the baby on an electronic scale, record stable weight data. Healthcare workers or midwives fill out the delivery information of the newborn in the regional maternal and child information system. The logical settings of the system have been corrected to ensure the convincing records. Finally, the information will be transferred to the Guangdong Birth Certificate System. After the data being imported, the midwife director and the hospital doctor director need to confirm the birth information. Before the birth certificate is issued, the department of medical management and the parents should check the birth information again. All information is verified by medical professionals. The birth registration database contains the date of birth, gestational age in week, birth weight, sex of the infant, parity, age of the mother and registered residence of the mother. All live newborns were included in the study except for stillbirths, deaths within days of birth and birth defects. To reduce bias, the subset of births was limited to singleton live births with 22-42 completed weeks gestation. ${ }^{19}$ After further excluding births with implausible birth weights (less than $500 \mathrm{~g})^{20}$ and verifying data, we included a total number of 2914198 births in our analysis.

\section{Data analysis}

We described basic characteristics of the newborns and mothers and the rates of PTB, LBW and SGA according to the studied characteristics by year and compared the estimates using $\chi^{2}$ test. In order to observe the temporal trends in the occurrence of PTB, LBW and SGA in the study site, we calculated daily rates of PTB (daily number of live births with gestational age less than 37 weeks/daily number of live births $\times 100 \%$ ), ${ }^{3}$ daily rates of LBW (daily number of live births with birth weight less than $2500 \mathrm{~g}$ / daily number of live births $\times 100 \%),{ }^{4}$ daily rates of SGA (daily number of live births with birth weight less than the 10th percentile of the normal average birth weight at the same gestational age/daily number of live births at the same gestational age $\times 100 \%),{ }^{21}$ respectively. We determined the season of birth based on the birth date (spring: March-May, summer: June-August; autumn: September-November, winter: December-February). Heatmaps of weekly average rates of PTB, LBW and SGA were drew to investigate whether the rates exhibited an obvious seasonality. SAS software V.9.3 (SAS Institute, Cary, North Carolina, USA) was used for the statistical analyses. 


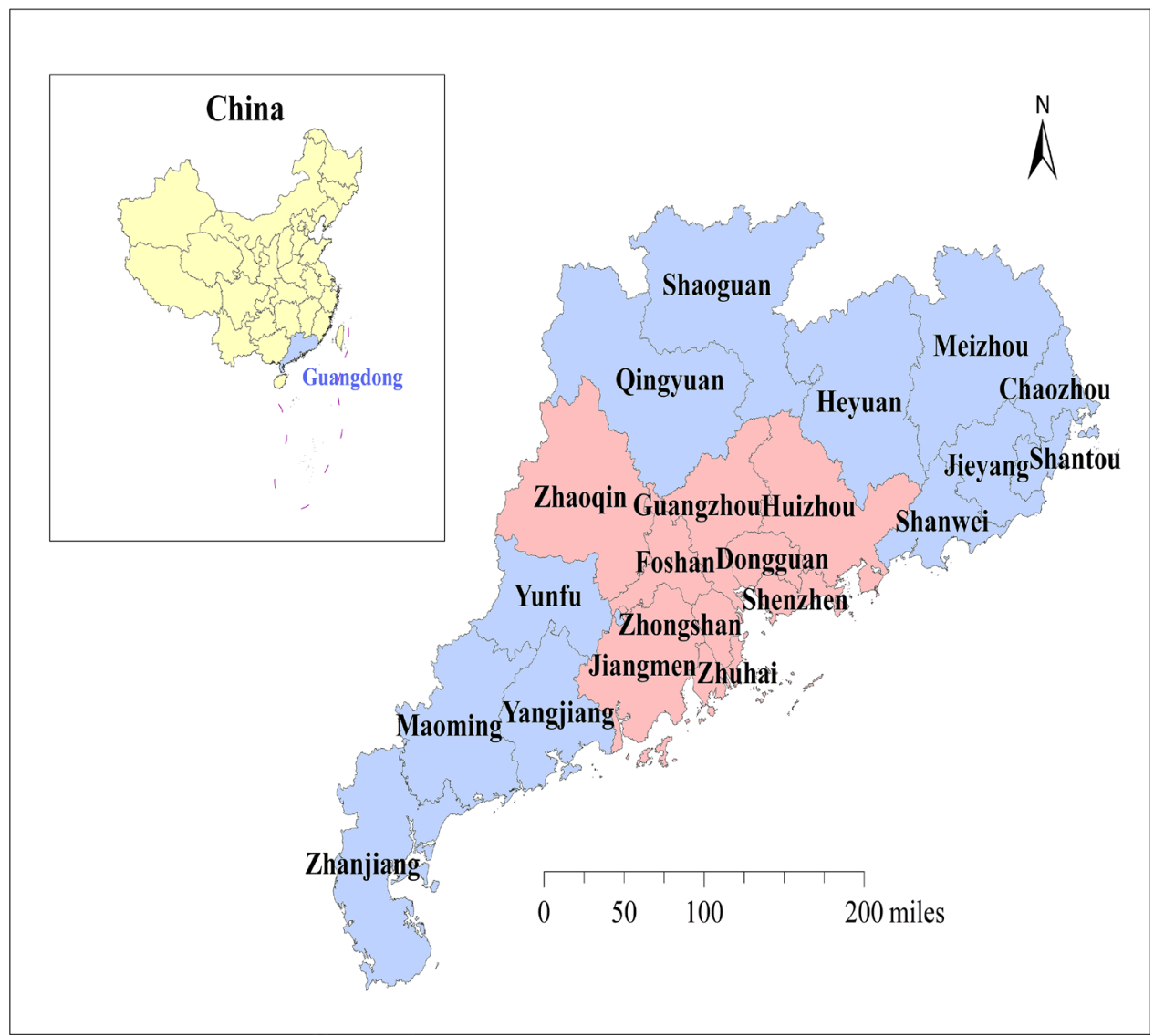

Figure 1 Geographical locations of the study. Guangdong province is located in south China, and there are 21 cities, namely Guangzhou, Shenzhen, Foshan, Dongguan, Zhuhai, Zhongshan, Zhaoqing, Huizhou, Jiangmen, Chaozhou, Shantou, Jieyang, Meizhou, Shanwei, Shaoguan, Heyuan, Qingyuan, Yunfu, Yangjiang, Maoming and Zhanjiang, included in this study. The Pearl River Delta regions were marked with pink, and the Non-Pearl River Delta regions were indicated by light blue.

According to economic conditions, Guangdong province can be divided into Pearl River Delta regions and Non-Pearl River Delta regions. Pearl River Delta regions are economically developed regions, including Guangzhou, Shenzhen, Foshan, Dongguan, Zhuhai, Zhongshan, Zhaoqing, Huizhou and Jiangmen cities. By contrast, Non-Pearl River Delta regions are relatively underdeveloped regions, including Shantou, Chaozhou, Jieyang, Shanwei, Zhanjiang, Maoming, Yangjiang, Yunfu, Shaoguan, Qingyuan, Meizhou and Heyuan cities. Besides, city boundary shape files of Guangdong province were publicly obtained from the National Geomatics Center of China (http://www.ngcc.cn/ngcc/) and used for disease mapping. We mapped the spatial distributions of rates for the adverse birth outcomes to investigate the spatial distributions pattern of the birth outcomes through 2014 to 2017. In addition, we calculated the Kulldorff's spatial scan statistic using the DCluster package within R software for purely spatial cluster detection of the adverse birth outcomes. All statistical tests were 2-tailed. P value less than 0.05 was considered to be statistically significant.

\section{RESULTS}

Figure 1 shows the geographical locations of the study in Guangdong province. Guangdong province is located in southern China and is also currently the most populous province in China. There were a total of 2917098 births in Guangdong province during the study period, and $1553948(53.27 \%)$ were boys. Approximately 22\% $(627,146)$ babies were born in 2015 , which is the lowest population of all births between 2014 and 2017. As illustrated in table 1, the proportion of mothers who aged less than 20, 20-24, 25-29, 30-34 and over 35 years old was $2.68 \%, 22.78 \%, 39.87 \%, 23.38 \%$ and $11.29 \%$, respectively. For the seasons of birth, the proportion of babies born in spring, summer, autumn and winter was $23.16 \%$, $24.61 \%, 27.57 \%$ and $24.66 \%$, respectively. There were 56748 (46.96\%) LBW of PTBs, while there were 63968 (52.93\%) LBW of term births. Regarding SGA infants, 2.47\% were PTBs, while $97.53 \%$ were term births.

Table 2 reveals that the rates of PTB, LBW and SGA according to demographic characteristics, residence address and birth seasons by year. Infants born from women aged 35 years and above have higher rates of LBW and PTB outcomes than women younger than 35 years old (all $\mathrm{p}<0.05)$. However, the rates of the difference were gradually decreasing from 2014 to 2017. From 2014 to 2016, there was a downward trend in the rates of SGA among pregnant women who aged $<35$ years old or $\geq 35$ years old. In 2017, the rates for SGA by two groups 


\begin{tabular}{|c|c|c|c|}
\hline Characteristic & Category & Frequency & Percentage \\
\hline \multirow{6}{*}{$\begin{array}{l}\text { Maternal age } \\
\text { (years) }\end{array}$} & $<20$ & 78116 & 2.68 \\
\hline & $20-24$ & 664443 & 22.78 \\
\hline & 25-29 & 1163071 & 39.87 \\
\hline & $30-34$ & 682067 & 23.38 \\
\hline & $\geq 35$ & 329378 & 11.29 \\
\hline & Missing & 23 & 0.00 \\
\hline \multirow[t]{2}{*}{ Inhabited city } & $\begin{array}{l}\text { Pearl River } \\
\text { Delta region }\end{array}$ & 1254102 & 42.99 \\
\hline & $\begin{array}{l}\text { Non-Pearl } \\
\text { River Delta } \\
\text { region }\end{array}$ & 1662996 & 57.01 \\
\hline \multirow[t]{3}{*}{ Infant sex } & Boy & 1553948 & 53.27 \\
\hline & Girl & 1363125 & 46.73 \\
\hline & Missing & 25 & 0.00 \\
\hline \multirow[t]{4}{*}{ Year of birth } & 2014 & 763518 & 26.17 \\
\hline & 2015 & 627146 & 21.50 \\
\hline & 2016 & 794755 & 27.24 \\
\hline & 2017 & 731679 & 25.08 \\
\hline \multirow[t]{4}{*}{ Season of birth } & Spring & 675595 & 23.16 \\
\hline & Summer & 717762 & 24.61 \\
\hline & Autumn & 804275 & 27.57 \\
\hline & Winter & 719466 & 24.66 \\
\hline \multirow[t]{3}{*}{ Preterm birth } & Yes & 121245 & 4.16 \\
\hline & No & 2792953 & 95.74 \\
\hline & Missing & 2900 & 0.10 \\
\hline \multirow[t]{3}{*}{ LBW } & Yes & 120846 & 4.14 \\
\hline & No & 2796122 & 95.85 \\
\hline & Missing & 130 & 0.00 \\
\hline \multirow[t]{3}{*}{ SGA } & Yes & 384637 & 12.86 \\
\hline & No & 2529522 & 82.88 \\
\hline & Missing & 2939 & 4.26 \\
\hline \multirow[t]{3}{*}{ LBW (Yes) } & Preterm & 56748 & 46.96 \\
\hline & Full-term & 63968 & 52.93 \\
\hline & Missing & 130 & 0.11 \\
\hline \multirow[t]{2}{*}{ SGA (Yes) } & Preterm & 9499 & 2.47 \\
\hline & Full-term & 375138 & 97.53 \\
\hline
\end{tabular}

LBW, low birth weight; SGA, small for gestational age.

of pregnant women rose slightly. Generally, infants who were born in the Pearl River Delta regions had higher rates of PTB and LBW than those who were born in NonPearl River Delta regions in Guangdong (all $\mathrm{p}<0.05$ ). However, infants who were born in the Pearl River Delta regions tended to have lower rates of SGA than those who were born in Non-Pearl River Delta regions (all $\mathrm{p}<0.05$ ). Boy and girl babies tended to be similar in the rates of the outcomes. We found the PTB rates of boys were higher than that of girls $($ all $\mathrm{p}<0.05)$, among which the highest rate was in $2016(5.02 \%)$. Besides, the LBW rates of girls were higher than that of boys (all $\mathrm{p}<0.05$ ), among which the highest rate was in 2017 (4.78\%). For SGA, the highest rate was $14.46 \%$ in the girls group. In addition, the rates of PTB, LBW and SGA statistically varied among seasons of birth, respectively $($ all $\mathrm{p}<0.05)$. For PTB, the highest rates were clustered in winter. For LBW, the highest rates did not show cluster tendency of season. However, for SGA, the highest rates were clustered in summer or autumn.

Figure 2 depicts daily time-series plots of the rates for the adverse pregnancy outcomes including PTB, LBW and SGA. On visual inspection, the rates of PTB, LBW and SGA show, to some degree, seasonal fluctuation trends, especially for the outcomes of PTB and SGA. In 2014, the rate of PTB ranged from 2.45\% in October to $6.06 \%$ in February. The period of highest rates of PTB was between December and February. In 2015 and 2016, the rates of PTB in November were the lowest in the course of the year. In contrast, in 2016 and 2017, the highest rates of PTB were in October. In 2014, infants had a peak rate $(5.61 \%)$ of LBW in September. Infants born from February to April were least likely to suffer from LBW, with the lowest rate $(2.55 \%)$ in March. In 2017, there was a similar pattern for LBW infants with the rate $(2.80 \%)$ in February, which clearly lower than the figure between September and October. Additionally, the peak rate $(6.30 \%)$ of LBW occurred in October. The average of daily rates of SGA was $14.30 \%$ in this study. During the period from 2014 to 2017, infants were least likely to suffer from SGA between January and March, which is similar to the outcome of LBW. In addition, infants were most likely to suffer from SGA between September and October.

Figure 3 depicts the heatmaps of weekly average rates for PTB, LBW and SGA across cities in Guangdong province, from 2014 to 2017. For most cities, there was a remarkable seasonality in the rates of the adverse pregnancy outcomes, especially for LBW and SGA.

Figure 4 shows the spatial distributions of PTB rates, as expressed in per 100 persons, in Guangdong, from 2014 to 2017. The figure revealed that the rates of PTB were relatively high in the Pearl River Delta regions. For the years of 2014 and 2015, the highest rates of PTB were in Zhongshan and Foshan cities, located in Pearl River Delta regions. In 2016, the city of Foshan had the highest rate of PTB. Additionally, we observed that Yunfu which is located near the Pearl River Delta region had a distinctly high rate of PTB in 2016. In 2017, the city of Zhongshan has the highest rate of PTB. We observed spatial heterogeneity of PTB outcome across the study time period in Guangdong province (online supplementary figure S1 and table S1), and the most likely cluster appearing in the Pearl River Delta was detected.

Similarly, the spatial heterogeneity of LBW and SGA was also observed in Guangdong province (online supplementary figures S2, S3 and table S1). Figures 5 and 6 depict the maps of spatial distributions of rates for 
Table 2 Rates of PTB, LBW and SGA according to demographic characteristics, residence address and birth season by year

\begin{tabular}{|c|c|c|c|c|c|c|c|}
\hline \multirow[b]{2}{*}{ Year } & \multirow[b]{2}{*}{ Characteristic } & \multicolumn{5}{|c|}{ Adverse pregnancy outcome } & \multirow[b]{2}{*}{$P$ value } \\
\hline & & PTB (\%) & $P$ value & LBW (\%) & $P$ value & SGA (\%) & \\
\hline 2014 & Maternal age (years) & & $<0.0001$ & & $<0.0001$ & & $<0.0001$ \\
\hline & $<35$ & 3.79 & & 4.04 & & 14.39 & \\
\hline & $\geq 35$ & 6.43 & & 5.17 & & 10.54 & \\
\hline & Inhabited city & & $<0.0001$ & & $<0.0001$ & & $<0.0001$ \\
\hline & Pearl River Delta region & 5.03 & & 4.49 & & 11.75 & \\
\hline & Non-Pearl River Delta region & 3.39 & & 3.91 & & 15.43 & \\
\hline & Infant sex & & $<0.0001$ & & $<0.0001$ & & $<0.0001$ \\
\hline & Boy & 4.43 & & 3.63 & & 13.81 & \\
\hline & Girl & 3.47 & & 4.68 & & 14.46 & \\
\hline & Season of birth & & $<0.0001$ & & 0.0003 & & $<0.0001$ \\
\hline & Spring & 3.78 & & 3.96 & & 13.85 & \\
\hline & Summer & 3.85 & & 4.19 & & 14.88 & \\
\hline & Autumn & 3.8 & & 4.21 & & 14.88 & \\
\hline & Winter & 4.48 & & 4.1 & & 12.8 & \\
\hline 2015 & Maternal age (years) & & $<0.0001$ & & $<0.0001$ & & $<0.0001$ \\
\hline & $<35$ & 3.79 & & 4.05 & & 14.09 & \\
\hline & $\geq 35$ & 6.5 & & 4.91 & & 9.51 & \\
\hline & Inhabited city & & $<0.0001$ & & $<0.0001$ & & $<0.0001$ \\
\hline & Pearl River Delta region & 5.13 & & 4.48 & & 11.06 & \\
\hline & Non-Pearl River Delta region & 3.43 & & 3.93 & & 15.12 & \\
\hline & Infant sex & & $<0.0001$ & & $<0.0001$ & & $<0.0001$ \\
\hline & Boy & 4.51 & & 3.68 & & 13.43 & \\
\hline & Girl & 3.47 & & 4.63 & & 14.01 & \\
\hline & Season of birth & & $<0.0001$ & & $<0.0001$ & & $<0.0001$ \\
\hline & Spring & 4.02 & & 4.08 & & 13.36 & \\
\hline & Summer & 4.03 & & 4.33 & & 14.59 & \\
\hline & Autumn & 3.87 & & 4.19 & & 14.24 & \\
\hline & Winter & 4.2 & & 3.87 & & 12.53 & \\
\hline 2016 & Maternal age (years) & & $<0.0001$ & & $<0.0001$ & & $<0.0001$ \\
\hline & $<35$ & 4.24 & & 3.98 & & 12.4 & \\
\hline & $\geq 35$ & 6.87 & & 4.88 & & 8.5 & \\
\hline & Inhabited city & & $<0.0001$ & & $<0.0001$ & & $<0.0001$ \\
\hline & Pearl River Delta region & 5.28 & & 4.25 & & 9.9 & \\
\hline & Non-Pearl River Delta region & 3.82 & & 3.92 & & 13.93 & \\
\hline & Infant sex & & $<0.0001$ & & $<0.0001$ & & $<0.0001$ \\
\hline & Boy & 5.02 & & 3.61 & & 11.7 & \\
\hline & Girl & 4 & & 4.62 & & 12.23 & \\
\hline & Season of birth & & 0.0011 & & $<0.0001$ & & $<0.0001$ \\
\hline & Spring & 4.49 & & 4.02 & & 11.76 & \\
\hline & Summer & 4.66 & & 4.29 & & 12.37 & \\
\hline & Autumn & 4.43 & & 4.08 & & 12.01 & \\
\hline & Winter & 4.6 & & 3.93 & & 11.58 & \\
\hline 2017 & Maternal age (years) & & $<0.0001$ & & $<0.0001$ & & $<0.0001$ \\
\hline & $<35$ & 3.67 & & 4.11 & & 13.85 & \\
\hline
\end{tabular}


Table 2 Continued

\begin{tabular}{|c|c|c|c|c|c|c|c|}
\hline \multirow[b]{2}{*}{ Year } & \multirow[b]{2}{*}{ Characteristic } & \multicolumn{5}{|c|}{ Adverse pregnancy outcome } & \multirow[b]{2}{*}{$P$ value } \\
\hline & & PTB (\%) & P value & LBW (\%) & $P$ value & SGA (\%) & \\
\hline & $\geq 35$ & 5.83 & & 4.89 & & 10.05 & \\
\hline & Pearl River Delta region & 4.27 & & 4.42 & & 12.56 & \\
\hline & Non-Pearl River Delta region & 3.82 & & 4.08 & & 13.82 & \\
\hline & Boy & 4.53 & & 3.78 & & 13.13 & \\
\hline & Girl & 3.5 & & 4.78 & & 13.24 & \\
\hline & Season of birth & & $<0.0001$ & & $<0.0001$ & & $<0.0001$ \\
\hline & Spring & 3.91 & & 4.14 & & 12.57 & \\
\hline & Summer & 3.94 & & 4.36 & & 13.91 & \\
\hline
\end{tabular}

LBW, low birth weight; PTB, preterm birth; SGA, small for gestational age.

LBW and SGA in Guangdong, respectively. In the years of 2014 and 2015, the rates of LBW were relatively high in the cities including Zhaoqing, Jiangmen, Zhongshan, Foshan, Dongguan and Guangzhou. In 2016, the rates of
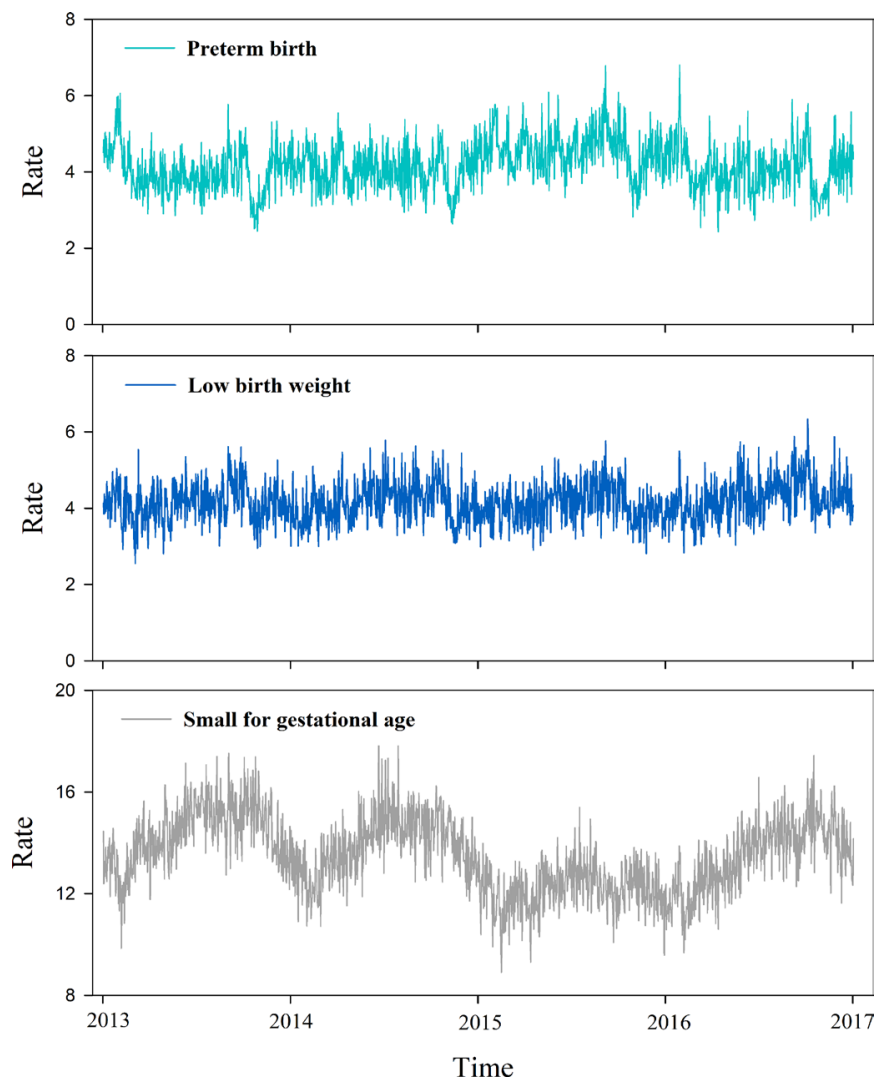

Figure 2 Daily time-series plots of rates for the adverse pregnancy outcomes including PTB, LBW and SGA in Guangdong province, China, from 1 January 2014 to 31 December 2017. LBW, low birth weight; PTB, preterm birth; SGA, small for gestational age.
LBW were relatively high in Zhaoqing, Yunfu and Foshan. In 2017, the rates of LBW were relatively high in Zhaoqing, Yunfu, Jiangmen and Foshan. For the outcomes of SGA, the cities including Shantou, Zhaoqing and Yunfu had higher rates than other cities from 2014 to 2017. In addition, the rate of SGA in Foshan was also high in 2017.

\section{DISCUSSION}

Our study analysed a total number of 2917098 live births to reveal the characteristics of the temporal trends and spatial distributions of PTB, LBW and SGA in Guangdong province from 2014 to 2017. This study reveals the overall situation and regional differences of fertility among local residents in Guangdong province and provides more recent data about the reproductive status of local pregnant women. These findings will be beneficial to subsequently explore on the causes of differences in the fertility in Guangdong province.

For PTB, Beck et at reported in a systematic review that 9.6\% were PTBs among 12.9 million births worldwide in 2005. A study estimated 14.9 million babies were PTBs in 2010, accounting for $11.1 \%$ of all live births worldwide, ranging from about $5 \%$ in several European countries to $18 \%$ in some African countries. ${ }^{22}$ A study revealed that PTB rate was around $4.75 \%$ among 10 counties and cities in China, based on Perinatal Healthcare Surveillance System from 1993 to $2005 .{ }^{23}$ As the United Nations International Children's Emergency Fund (UNICEF) announced in 2007, the rates of LBW in China were still lower than those of some developed countries, such as the USA $(8 \%)$, Australia $(7 \%)$, the UK $(8 \%)$, Canada $(6 \%)$ and Japan $(8 \%) .{ }^{10}$ However, the rate of LBW in China was slightly higher than the figure in South Korea (4\%). According to a survey covering 14 provinces in China, the LBW rate in 1998 was $5.87 \%$ and it decreased to $4.6 \%$ 
PTB

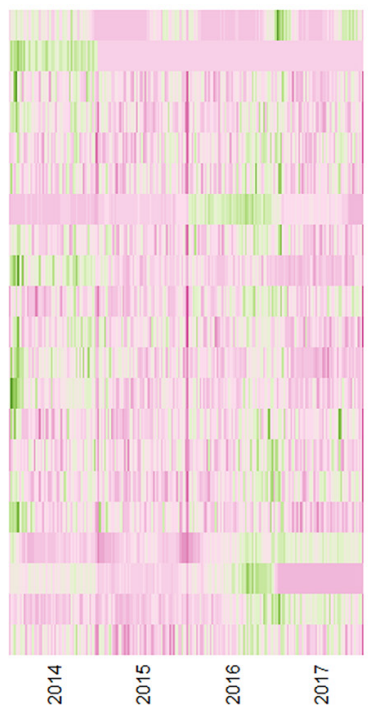

LBW

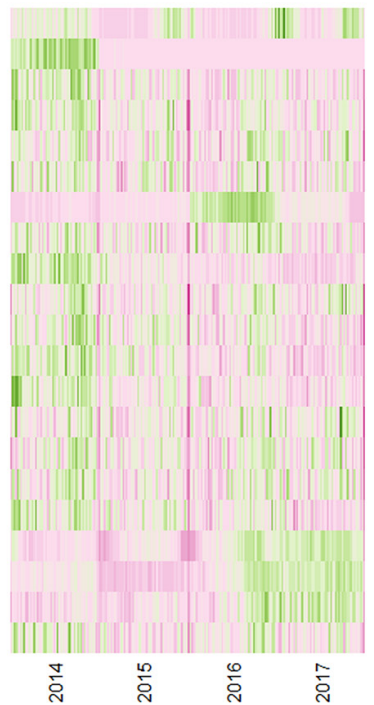

SGA

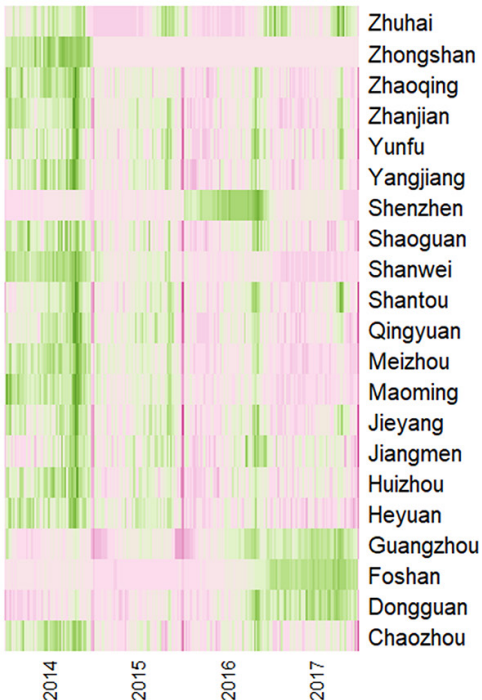

Figure 3 Heatmaps of weekly counts for the adverse pregnancy outcomes including PTB, LBW and SGA across cities in Guangdong province, China, from 1 January 2014 to 31 December 2017. LBW, low birth weight; PTB, preterm birth; SGA, small for gestational age.

in $2006 .{ }^{24}$ For the worldwide rates of SGA, a previous study showed the rates were relatively high in Cambodia (18.8\%), Nepal (17.9\%), the Occupied Palestinian Territory $(16.1 \%)$ and Japan $(16.0 \%)$, while rates were relatively low in Afghanistan (4.8\%), Uganda (6.6\%) and Thailand $(9.7 \%) .{ }^{12}$ In addition, a recent cross-sectional population-based study revealed that the rate of SGA was $12.93 \%$ from 1 January 2017 to 31 October 2017 in southern China. ${ }^{25}$ However, the study was based on a relatively small size of data. Our study, based on a large size of data, revealed that the rates of PTB, LBW and SGA in Guangdong province were relatively low, compared with other countries in the world.

The data represent statistically significant seasonal variations of births and adverse birth outcomes in Guangdong province, China. Seasonal patterns of birth outcomes were not consistent, which may reflect different aetiologies and risk factors of time for each of the examined birth outcomes. For the rates of PTB, the highest number almost occurred in winter. Besides, for SGA, the highest
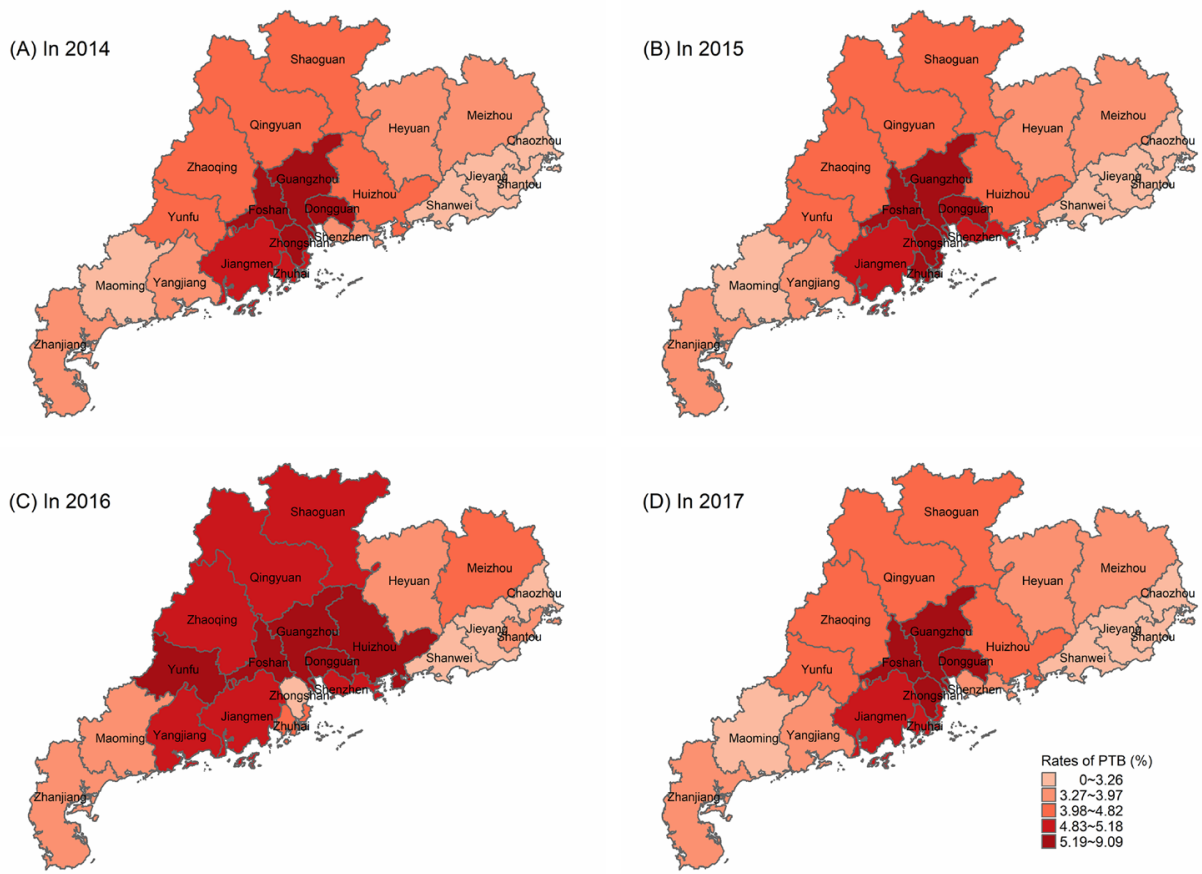

Figure 4 Spatial distributions of rates of PTB, in Guangdong province, China, from 1 January 2014 to 31 December 2017. (A) Spatial distributions of PTB rates in 2014. (B) Spatial distributions of PTB rates in 2015. (C) Spatial distributions of PTB rates in 2016. (D) Spatial distributions of PTB rates in 2017. PTB, preterm birth. 

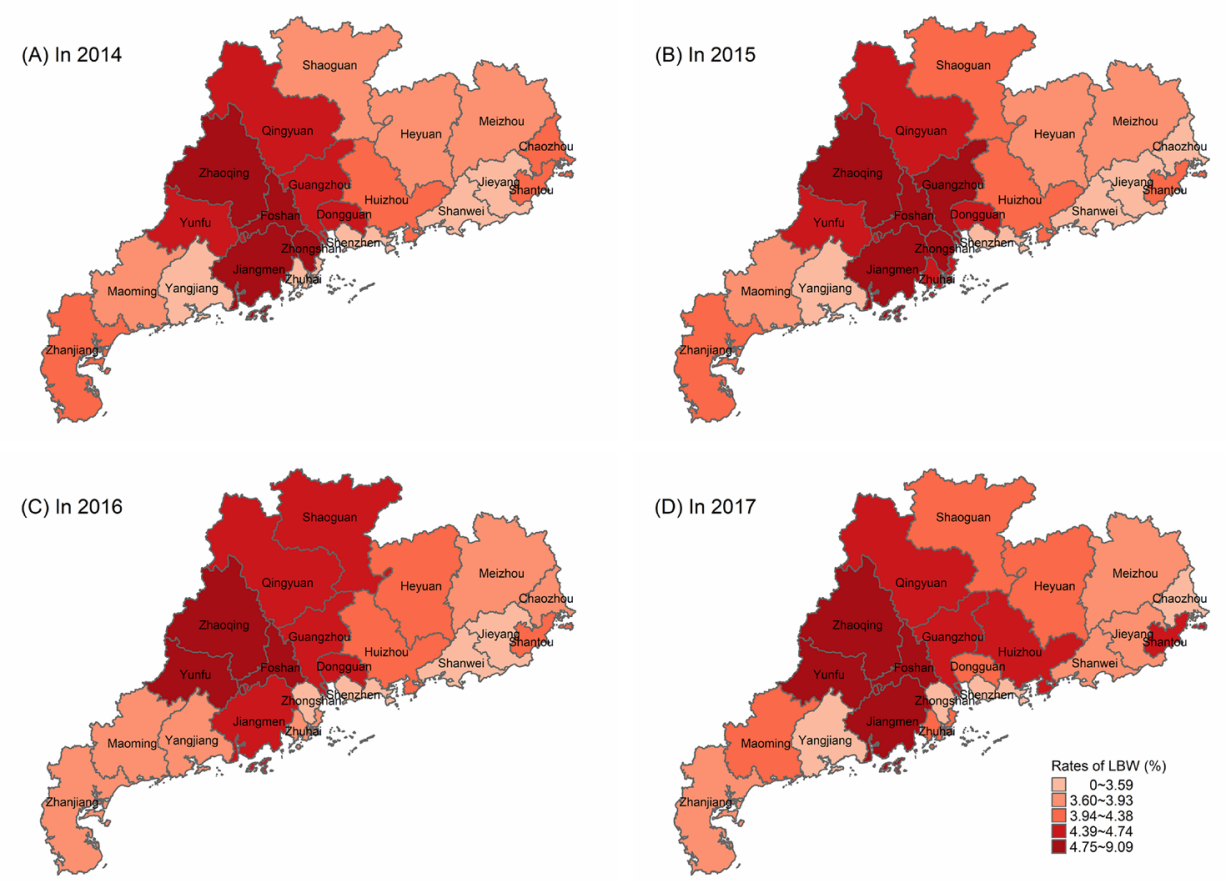

Figure 5 Spatial distributions of rates of LBW, in Guangdong province, China, from 1 January 2014 to 31 December 2017. (A) Spatial distributions of LBW rates in 2014. (B) Spatial distributions of LBW rates in 2015. (C) Spatial distributions of LBW rates in 2016. (D) Spatial distributions of LBW rates in 2017. LBW, low birth weight.

rates were in summer or autumn from 2014 to 2017. Studies in developed countries such as Greece, ${ }^{26}$ Atlanta $^{27}$ and South Korea ${ }^{28}$ revealed that PTB has a seasonal trend. LBW was also found seasonal trends. ${ }^{29}$ A study revealed that PTB and SGA showed divergent patterns of seasonality in rural African community. ${ }^{30}$ Seasonality of PTB,
LBW and SGA was also found in Nepal. Our study indicated that the rate of PTB in November was the lowest in 2015 and 2016, while the rate in October was the highest in 2016 and 2017. Hughes $e t a l^{31}$ also found infants were least likely to suffer from SGA from January to March. In contrast, Infants were most likely to suffer from SGA from
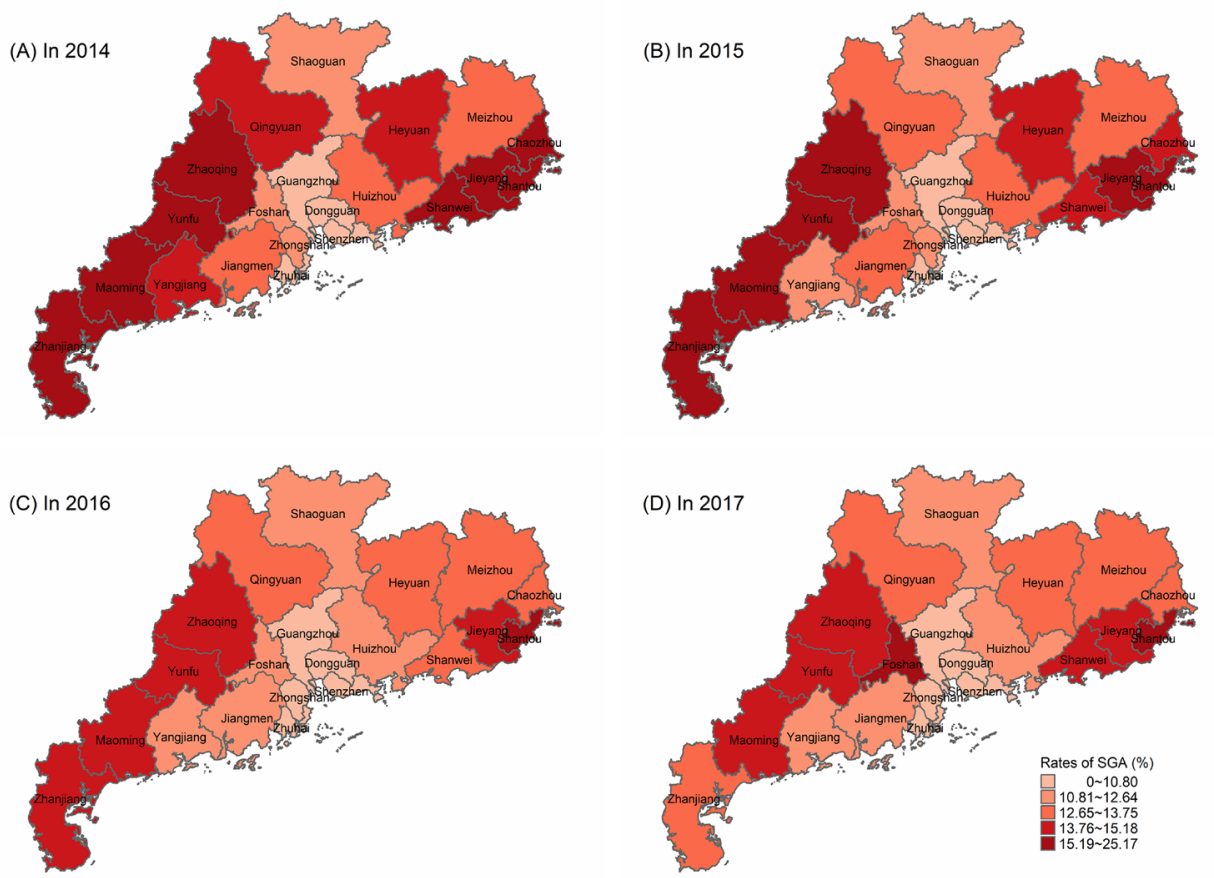

Figure 6 Spatial distributions of rates of SGA, in Guangdong province, China, from 1 January 2014 to 31 December 2017. (A) Spatial distributions of SGA rates in 2014. (B) Spatial distributions of SGA rates in 2015. (C) Spatial distributions of SGA rates in 2016. (D) Spatial distributions of SGA rates in 2017. SGA, small for gestational age. 
June to August and in November. In our study, the rates of SGA peaked in the time period between September and October, and the rates were relatively low from January to March. In some countries, it was also reported that PTB had an obvious seasonal trend. In London, ${ }^{32}$ babies born in winter were more likely to suffer from PTB compared with those born in spring. In Gambia, ${ }^{30}$ the rates of PTB peaked twice in a year, once in the hunger season in July and once in October. However, a previous study from the USA reported no seasonality in the rates of PTB. ${ }^{33}$ We speculate that the inconsistent results from different countries were partly due to the differences in the study population related to geography, culture and socioeconomics. Environmental factors including temperature, humidity and sunlight have been associated with birth outcomes. According to an animal model, a biological explanation for increasing the risk of PTB is that high temperatures increase the chances of dehydration. ${ }^{34}$ This effect increases the risk of PTB due to decreased uterine blood flow and increased secretion of prostaglandins and oxytocin. Another hypothesis is that the effect of sunlight on vitamin D levels may affect fetal growth. ${ }^{35} \mathrm{~A}$ study indicated that seasonal patterns are potential representatives of various environmental exposures. ${ }^{36}$

In terms of spatial factors, the PTB, LBW and SGA rates in the Pearl River Delta region were significantly different from those in the non-Pearl River Delta region. A regional analysis in Japan revealed that incidence of PTB was $3.2 \%$ in coastal areas and $5.0 \%$ in inland areas, respectively, and the incidence of $\mathrm{LBW}$ was $6.5 \%$ in the coastal areas and $8.5 \%$ in the inland areas. ${ }^{37}$ Our results of geographical distributions of the adverse pregnancy outcomes were basically consistent with the results from Brazilian regions, in which a higher LBW rates were observed in the developed regions compared with less developed regions. ${ }^{38}$ Overall, from 2014 to 2017, the high rates of PTB and LBW expanded from the Pearl River Delta region to the Non-Pearl River Delta regions. The trend of LBW rates increased in less developed areas of Guangdong province year by year. Previous studies also suggested that PTB is often associated with LBW, and their risk factors are similar. ${ }^{39} 40$ Our study indicated that the rates of SGA in the non-Pearl River Delta regions were generally higher than the Pearl River Delta regions. Previous study suggested that adverse pregnancy outcomes can be increased by preconception risk factors and lifestyles. ${ }^{41}$ As we know, there are obvious regional differences in the level of social-economic development in Guangdong province. ${ }^{42}$ These regional factors may have a direct impact on the fertility status and reproductive outcome of the local population. In China, the Pearl River Delta region has better economic situation, education condition and nutritional support than the nonPearl River Delta regions. Therefore, according to our actual situation, we need to pay more attention to relatively poor regions. We recommend increasing investment in its economic, medical and health resources. Previous study indicated that regional factors may affect birth outcomes through psychosocial processes associated with health behaviour, physiological stress hormones or increased susceptibility to infection. ${ }^{43}$ In the future work, we hope to further explore this topic by introducing more variables into the spatiotemporal model, rather than just economic conditions. Because there are few reports on the regional distribution of adverse pregnancy outcomes in China, the contribution of this study is to analyse the characteristics of adverse pregnancy outcomes in Guangdong province from two aspects: time trend and geographical distribution.

In fact, it is often difficult for developing countries to obtain accurate and complete demographic data and medical records for maternal delivery. This present study made use of high-quality data of birth certificate from a structured database of birth certificate in Guangdong province. The results of this study involving a large cohort of live births provide a clear description of temporal trends and spatial distributions of PTB, LBW and SGA in Guangdong province, which can be a high-quality baseline indicator for the researchers and decision makers of the public health.

This study does have several limitations. First, this study was just a descriptive analysis of temporal trends and spatial distributions of the adverse pregnancy outcomes and unable to identify the causal relationship between spatiotemporal factors and adverse pregnancy outcomes. Although we used time trend profiles to roughly observe seasonal patterns, we did not consider potential factors that are difficult to measure, such as maternal infections and nutritional deficiencies. Second, it should note that there may have some delays in reporting birth certificate data at small hospitals in different cities, which can also have a potential impact on our study.

In summary, our study is one of the few studies based on a large cohort of newborns to understand the public health problem of adverse birth outcomes in China. The findings of this study contribute to the understanding of the aetiology and epidemiology of PTB, LBW and SGA.

\section{Author affiliations}

${ }^{1}$ Guangdong Women and Children Hospital, Guangzhou, China

${ }^{2}$ Department of Preventive Medicine, Shantou University Medical College, Shantou, China

${ }^{3}$ Department of Clinical Medicine, Shantou University Medical College, Shantou, China

${ }^{4}$ Department of Hepatology and Infectious Diseases, Second Affiliated Hospital of Shantou University Medical College, Shantou, Guangdong, China

${ }^{5}$ Epidemiological Research Office of Key Laboratory of Male Reproduction and Genetics (National Health Commission of PRC), Family Planning Special Hospital of Guangdong Province, Guangzhou, China

Contributors HM, WL, BL and FY contributed equally in this study and they are joint first authors. HM, PG and QZ conceived of or designed study. HM, BL, WL, FY, YC, RC, YW and PG performed research. HM, PG and FY analysed data. PG, HM, JL, $\mathrm{FY}$ and $\mathrm{QZ}$ wrote and revised the paper. PG obtained the funding.

Funding This work was supported by the National Natural Science Youth Fund of China (No. 81703323).

Disclaimer The funder had no role in study design, data collection and analysis, decision to publish, or preparation of the manuscript. 
Map disclaimer The depiction of boundaries on this map does not imply the expression of any opinion whatsoever on the part of BMJ (or any member of its group) concerning the legal status of any country, territory, jurisdiction or area or of its authorities. This map is provided without any warranty of any kind, either express or implied.

\section{Competing interests None declared.}

Patient consent for publication Not required.

Ethics approval This study was approved by the ethics committee of Guangdong Woman \& Children Hospital (Shantou, China). The approval number is 201601011

Provenance and peer review Not commissioned; externally peer reviewed. Data availability statement No data are available.

Open access This is an open access article distributed in accordance with the Creative Commons Attribution Non Commercial (CC BY-NC 4.0) license, which permits others to distribute, remix, adapt, build upon this work non-commercially, and license their derivative works on different terms, provided the original work is properly cited, appropriate credit is given, any changes made indicated, and the use is non-commercial. See: http://creativecommons.org/licenses/by-nc/4.0/.

\section{REFERENCES}

1 Mathews TJ, MacDorman MF. Infant mortality statistics from the 2008 period linked birth/infant death data set. Natl Vital Stat Rep 2012;60:1-27.

2 Owen LS, Manley BJ, Davis PG, et al. The evolution of modern respiratory care for preterm infants. The Lancet 2017;389:1649-59.

3 WHO. Who: recommended definitions, terminology and format for statistical tables related to the perinatal period and use of a new certificate for cause of perinatal deaths. modifications recommended by FIGO as amended October 14, 1976. Acta ObstetGynecolScand 1977;56:247-53.

4 Wardlaw T, Blanc A, Zupan J, et al. Low birthweight: country regional and global estimates. New York New York: Unicef, 2004.

5 Saenger P, Czernichow P, Hughes I, et al. Small for gestational age: short stature and beyond. Endocr Rev 2007;28:219-51.

6 Beck S, Wojdyla D, Say L, et al. The worldwide incidence of preterm birth: a systematic review of maternal mortality and morbidity. Bull World Health Organ 2010;88:31-8.

7 Lawn JE, Cousens SN, Darmstadt GL, et al. 1 year after the Lancet neonatal survival Series - was the call for action heard? The Lancet 2006;367:1541-7.

8 ACD L, Katz JS, Blencowe HM, et al. National and regional estimates of term and preterm babies born small for gestational age in 138 lowincome and middle-income countries in 2010. Lancet Glob Health 2013;1:e26-36

9 JR H, Liu Y, Xia XY, et al. Ambient temperature and the risk of preterm birth in Guangzhou, China (2001-2011). Environ Health Perspect 2016;124:1100-6.

10 Chen Y, Wu L, Zhang W, et al. Delivery modes and pregnancy outcomes of low birth weight infants in China. J Perinatol 2016;36:41-6.

11 Tamura N, Hanaoka T, Ito K, et al. Different risk factors for very low birth weight, Term-Small-for-Gestational-Age, or preterm birth in Japan. Int J Environ Res Public Health 2018;15:369.

12 Ota E, Ganchimeg T, Morisaki N, et al. Risk factors and adverse perinatal outcomes among term and preterm infants born small-forgestational-age: secondary analyses of the who Multi-Country survey on maternal and newborn health. PLoS One 2014;9:e105155.

13 Strand LB, Barnett AG, Tong S. The influence of season and ambient temperature on birth outcomes: a review of the epidemiological literature. Environ Res 2011;111:451-62.

14 Ha S, Zhu Y, Liu D, et al. Ambient temperature and air quality in relation to small for gestational age and term low birthweight. Environ Res 2017;155:394-400.

15 Lee SJ, Hajat S, Steer PJ, et al. A time-series analysis of any shortterm effects of meteorological and air pollution factors on preterm births in London, UK. Environ Res 2008;106:185-94.

16 Tustin K, Gross J, Hayne H. Maternal exposure to first-trimester sunshine is associated with increased birth weight in human infants. Dev Psychobiol 2004;45:221-30.
17 Madsen C, Gehring U, Erik Walker S, et al. Ambient air pollution exposure, residential mobility and term birth weight in Oslo, Norway. Environ Res 2010;110:363-71.

$18 \mathrm{Li} \mathrm{L}$, Wang Y. What drives the aerosol distribution in Guangdong - the most developed province in Southern China? Sci Rep 2015;4:5972.

19 Johnson S, Bobb JF, Ito K, et al. Ambient fine particulate matter, nitrogen dioxide, and preterm birth in New York City. Environ Health Perspect 2016;124:1283-90.

20 Liu S, Krewski D, Shi Y, et al. Association between gaseous ambient air pollutants and adverse pregnancy outcomes in Vancouver Canada. Environ Health Perspect 2003;111:1773-8.

21 Li Z, Rong Z, Shulian Z, et al. Chinese neonatal birth weight curve for different gestational age. Chin J Pediatr 2015;53:97-103.

22 Blencowe H, Cousens S, Oestergaard MZ, et al. National, regional, and worldwide estimates of preterm birth rates in the year 2010 with time trends since 1990 for selected countries: a systematic analysis and implications. The Lancet 2012;379:2162-72.

23 Liu L, Liu J, Liu Y, et al. Prevalence of preterm birth among singletons in 10 counties(cities)of China, 1993-2005. Chin J Epidemiology 2007:1051-4.

24 Yu D-M, Zhao L-Y, Liu A-D, et al. [Incidence of low birth weight of neonates and the influencing factors in China]. Zhonghua $Y u$ Fang $Y_{i}$ Xue Za Zhi 2007;41 Suppl:150-4.

25 Yao F, Miao H, Li B, et al. New birthweight percentiles by sex and gestational age in southern China and its comparison with the INTERGROWTH-21st standard. Sci Rep 2018;8:7567.

26 Georgios B, Athanasios M, Derek H, et al. Preterm birth seasonality in Greece: an epidemiological study. Journal of Maternal-Fetal Medicine 2012:25:1406-12.

27 Darrow LA, Strickland MJ, Klein M, et al. Seasonality of birth and implications for temporal studies of preterm birth. Epidemiology 2009;20:699-706.

28 Woo Y, Ouh Y-T, Ahn KH, et al. Seasonal pattern of preterm births in Korea for 2000-2012. J Korean Med Sci 2016;31:1797-801.

29 Rousham EK, Gracey M. Seasonality of low birthweight in Indigenous Australians: an increase in pre-term birth or intrauterine growth retardation? Aust N Z J Public Health 1998;22:669-72.

30 Rayco-Solon P, Fulford AJ, Prentice AM. Differential effects of seasonality on preterm birth and intrauterine growth restriction in rural Africans. Am J Clin Nutr 2005;81:134-9.

31 Hughes MM, Katz J, Mullany LC, et al. Seasonality of birth outcomes in rural Sarlahi district, Nepal: a population-based prospective cohort. BMC Pregnancy Childbirth 2014;14:310.

32 Lee SJ, Steer PJ, Filippi V. Seasonal patterns and preterm birth: a systematic review of the literature and an analysis in a London-based cohort. BJOG: Int J O\&G 2006;113:1280-8.

33 Konte JM, Creasy RK, Laros RJ. California North coast preterm birth prevention project. Obstet Gynecol 1988;71:727-30.

34 Stan CM, Boulvain M, Pfister R, et al. Hydration for treatment of preterm labour. Cochrane Database Syst Rev 2013;003096:D3096.

35 McGrath JJ, Barnett AG, Eyles DW. The association between birth weight, season of birth and latitude. Ann Hum Biol 2005;32:547-59.

36 Kim SE, Honda Y, Hashizume M, et al. Seasonal analysis of the short-term effects of air pollution on daily mortality in northeast Asia. Science of The Total Environment 2017;576:850-7.

37 Sugawara J, Iwama N, Hoshiai T, et al. Regional birth outcomes after the 2011 great East Japan earthquake and tsunami in Miyagi Prefecture. Prehosp Disaster Med 2018;33:215-9.

38 de Souza Buriol VC, Hirakata V, Goldani MZ, et al. Temporal evolution of the risk factors associated with low birth weight rates in Brazilian capitals (1996-2011). Popul Health Metr 2016;14:15.

39 Trasande L, Malecha P, Attina TM, et al. And preterm birth: estimates of US. attributable burden and economic costs. Environ Health Persp 2016;124:1913-8.

40 Woodruff TJ, Parker JD, Darrow LA, et al. Methodological issues in studies of air pollution and reproductive health. Environ Res 2009;109:311-20.10.1016/j.envres.2008.12.012

41 Pandolfi E, Agricola E, Gonfiantini MV, et al. Women participating in a web-based preconception study have a high prevalence of risk factors for adverse pregnancy outcomes. BMC Pregnancy Childbirth 2014;14:169.

42 Yuan Y, Wu F. Regional social inequalities and social deprivation in Guangdong Province, China. Growth Change 2013;44:149-67.

43 Schempf A, Strobino D, O'Campo P. Neighborhood effects on birthweight: an exploration of psychosocial and behavioral pathways in Baltimore, 1995-1996. Soc Sci Med 2009;68:100-10. 